\title{
Wolbachia infection in the terrestrial isopod Oniscus asellus: sex ratio distortion and effect on fecundity
}

\author{
THIERRY RIGAUD*, JÉRÔME MOREAU \& PIERRE JUCHAULT \\ Université de Poitiers, Laboratoire de Génétique et Biologie des Populations de Crustacés, UMR CNRS 6556, \\ 40 avenue du Recteur Pineau, F-86022 Poitiers Cedex, France
}

\begin{abstract}
Maternally inherited Wolbachia bacteria are widespread in arthropods where they are responsible for various reproductive alterations. In terrestrial isopods (woodlice), Wolbachia may induce feminization or cytoplasmic incompatibility (CI), but their effect remains unknown in most host species. To increase our understanding of host/symbiont interactions in terrestrial isopods, the effect of Wolbachia was investigated in the oniscidean Oniscus asellus, mainly to discriminate between feminization and CI. The Wolbachia infection was not linked with a CI phenomenon, but females infected with Wolbachia produced female-biased broods compared with uninfected females. The fecundity of infected females was slightly lower than that of uninfected, but the number of young at the adult stage was similar between the two female categories. The experimental transfer of the symbiont into uninfected strains showed that Wolbachia was responsible for the feminization of a number of genetic males. In female-biased broods, Wolbachia were vertically transmitted to around $88 \%$ of the offspring, but the transmission rate was lower in the few male-biased progenies. The feminizing activity of these symbionts was not systematic, as many phenotypic males were infected. These results contrasted with what is known in another woodlouse species, and indicated that feminization has evolved in different ways in terrestrial isopods.
\end{abstract}

Keywords: Crustacea, cytoplasmic bacteria, feminization, Oniscidea, sex determination.

\section{Introduction}

Because of anisogamy, vertically transmitted cytoplasmic genes (organelles, endosymbionts, etc.) tend to be inherited exclusively from the mothers and have zero fitness in males. A Fisherian sex ratio (stable 1:1 sex ratio) is therefore not in the evolutionary interest of cytoplasmic elements, because their spread can increase if they favour the female sex in their host (Cosmides \& Tooby, 1981). Among other strategies (reviewed by Werren \& O'Neill, 1997), inherited cytoplasmic elements might induce the production of female-biased sex ratios.

A variety of such cytoplasmic sex ratio distorters is known in animals (Hurst, 1993). These include some endosymbionts that produce feminization (Rigaud, 1997; Kageyama et al., 1998). This phenomenon has been discovered in the terrestrial isopod (woodlouse) Armadillidium vulgare, a species where sex is normally determined by heterochromosomes (female heterogamety: females $\mathrm{WZ}$ and males $\mathrm{ZZ}$ ). In this species, the

*Correspondence. E-mail: thierry.rigaud@campus.univ-poitiers.fr microorganism responsible for feminization is a bacterium of the genus Wolbachia (Martin et al., 1973; Rousset et al., 1992). All infected individuals develop a female phenotype whatever their sex chromosome composition, and transmit the symbiont to most of their offspring (around $90 \%$ on average), generating female-biased sex ratios. In the wild, all infected females found so far have been of a ZZ (male) chromosomal composition, and only the uninfected offspring develop a male phenotype. In such infected strains, the sex ratio therefore depends only on the bacterial transmission rate. To put it in another way, the cytoplasmic Wolbachia represent the only female determinant in infected strains, whereas the male determinants are the $\mathrm{Z}$ chromosomes and autosomal genes repressing the transmission of the symbiont (Rigaud \& Juchault, 1992).

Wolbachia have recently been found in the majority of terrestrial isopods (Juchault et al., 1994; Bouchon et al., 1998), most of the time inducing feminization, with the exception of Porcellio dilatatus, where Wolbachiainduced cytoplasmic incompatibility (CI), a Wolbachia reproductive manipulation common in insects, is seen (Werren \& O'Neill, 1997). However, the effects 
Wolbachia has on host reproduction remain unknown in most isopods. The knowledge of these effects is important in understanding the evolution of host/endosymbiont relationships: to determine if feminization evolved in the same way in all infected species of this group, or if $\mathrm{CI}$ is more widespread in isopods. In these respects, the Wolbachia infection in Oniscus asellus is of interest. In this species, Wolbachia are present in several populations, there is no obvious sex ratio distortion linked with the infection, and some males are infected (Bouchon et al., 1998). The aim of the present study is to investigate the effects of Wolbachia on $O$. asellus reproduction, mainly to discriminate between the possibilities of feminization and CI.

\section{Materials and methods}

\section{Study in a natural population}

Animals were collected in spring 1995 in Quinçay (Vienne, France). The 14 females found gravid were reared in the laboratory at $20^{\circ} \mathrm{C}, \mathrm{L}: \mathrm{D} 18: 6$, on moistened soil with dead leaves and carrots as food. Each female was allowed to produce successive broods without remating (sperm are stored) until the end of the reproductive season. Offspring were reared in wider boxes to avoid competition, and were sorted by sex after sexual maturity, usually 3 months after birth. Each mother was dissected and DNA was extracted from the ovaries and the nerve chord (Bouchon et al., 1998). The presence/absence of Wolbachia was tested by PCR amplification of the bacterial 16S ribosomal gene, using specific primers, according to Bouchon et al. (1998). When no amplification was obtained, the quality of DNA template was tested using mitochondrial primers (Bouchon et al., 1998).

In woodlice, fecundity is positively correlated with female size (Sutton et al., 1984). To test the effect of infection on fecundity and fertility, 50 gravid females (carrying eggs in their marsupium) were collected in May 1998 at the same site. Their size (body length without antennae) was measured using a binocular microscope with a graduated ocular. Fecundity was examined in 25 females by counting the number of freshly laid eggs. Fertility was measured in the remaining 25 females by counting the number of young reaching the sexual differentiation (around 2 months after their birth). The sex ratio was also assessed in the broods of these last 25 females. A cubic function of the size was used in the analysis, in order to obtain a linear relationship between size and fecundity. The infection by Wolbachia was checked for each female by PCR, after DNA extraction from one ovary and the nerve chord.

\section{Injection experiments}

Ovaries from 10 infected $O$. asellus females from Quinçay were dissected and homogenized in $100 \mu \mathrm{L}$ of Ringer solution. The suspension was filtered through $1.2 \mu \mathrm{m}$ pores. Using a Hamilton syringe with a fine glass needle, $1 \mu \mathrm{L}$ of the suspension was injected into the body cavity of recipient (uninfected) individuals. The recipients were females and males collected at Sepvret (Deux-Sèvres, France). These inoculated individuals were designated as the $\mathrm{I}$ animals. The remaining individuals were kept as control ( $U$ animals). The absence of Wolbachia has previously been investigated in this strain (negative PCR assays, Bouchon et al. [1998]) and was verified regularly during the experiments by checking $U$ males and $U$ females sampled randomly in the crosses.

Five months after injection, crosses were made to investigate the sex ratio distortion and the compatibility of crosses between infected and uninfected individuals. Pair crosses (male $\times$ female) of each of the four crossing types were made: $\mathrm{U} \times \mathrm{U}, \mathrm{U} \times \mathrm{I}, \mathrm{I} \times \mathrm{U}, \mathrm{I} \times \mathrm{I}$. The broods were analysed as described above. To obtain the second generation (G2) after injection, several sisters from three broods of the first generation were crossed with uninfected males. To obtain the third generation (G3), four sisters from 12 broods of the G2 were crossed with uninfected males.

The rate of vertical transmission of Wolbachia was investigated by extracting DNA of male and female offspring from broods with different sex ratios, and testing the presence/absence of Wolbachia by PCR. All strongly male-biased broods ( $>80 \%$ males) were tested, whereas the test was carried out only in eight G3 progenies sampled randomly from broods with femalebiased or balanced sex ratios.

All the females tested by PCR were previously implanted with an androgenic gland removed from uninfected males. This gland is responsible for the synthesis of the androgenic hormone (AH). When implanted in a female, the gland continues to produce $\mathrm{AH}$ and is able to masculinize females (Legrand, 1958). In $A$. vulgare, females infected with Wolbachia are insensitive to this masculinization, an effect interpreted as a competition on the target tissues between a bacterial product and the AH (Juchault \& Legrand, 1985). The implant technique was similar to that described for Wolbachia injection, but the Wolbachia suspension was 
replaced by an androgenic gland previously dissected from a male.

\section{Results}

\section{Wolbachia infection in the wild}

Around half of the females collected in 1995 and in 1998 were infected by Wolbachia ( $\chi^{2}$ of difference from 1:1 ratio $=0.13 ; 1$ d.f.; $P>0.05$ ) (Table 1$)$. The infected females produced broods with higher proportions of females than uninfected ones (two-way ANOvA after arcsin transformation of the data: $F_{1,35}=12.56$; $P<0.001)$, whereas the sex ratio was neither significantly affected by the year of the sampling $\left(F_{1,35}=3.73\right.$; $P=0.062)$, nor by the interaction between the sample year and the infection status $\left(F_{1,35}=3.42 ; P=0.073\right)$. When size was taken as a covariable, the uninfected females produced slightly more eggs than infected ones (Fig. 1a; ANCOVA with the number of eggs as dependent variable: effect of size: $F_{1,22}=146.80, P<0.001$; effect of infection: $\left.F_{1,22}=5.39, P<0.05\right)$. However, there was no such difference in the numbers of young reaching the adult stage (Fig. 1b; ANCOVA with the number of young as dependent variable: effect of size: $F_{1,22}=19.65$, $P<0.001$; effect of infection: $F_{1,22}=0.003, P=0.96$ ).

\section{Effect of Wolbachia injection on the sex ratio}

The nine females and seven males tested in the I strains were found to be positive for the Wolbachia infection by PCR, whereas the $13 \mathrm{U}$ females tested were negative.

There was no significant effect of the cross type either on the average number of young produced per brood, or on the number of broods produced per female (Table 2). The size of the females was not measured during these experiments, so we can not estimate any effect of Wolbachia on female fertility. However, there was no strong decrease in fertility, typical of CI, in the cross type male $\mathrm{I} \times$ female $\mathrm{U}$. The sex ratio in the broods of $\mathrm{I}$ females was significantly female-biased (Table 2). There was no significant effect of male infection on sex ratio.
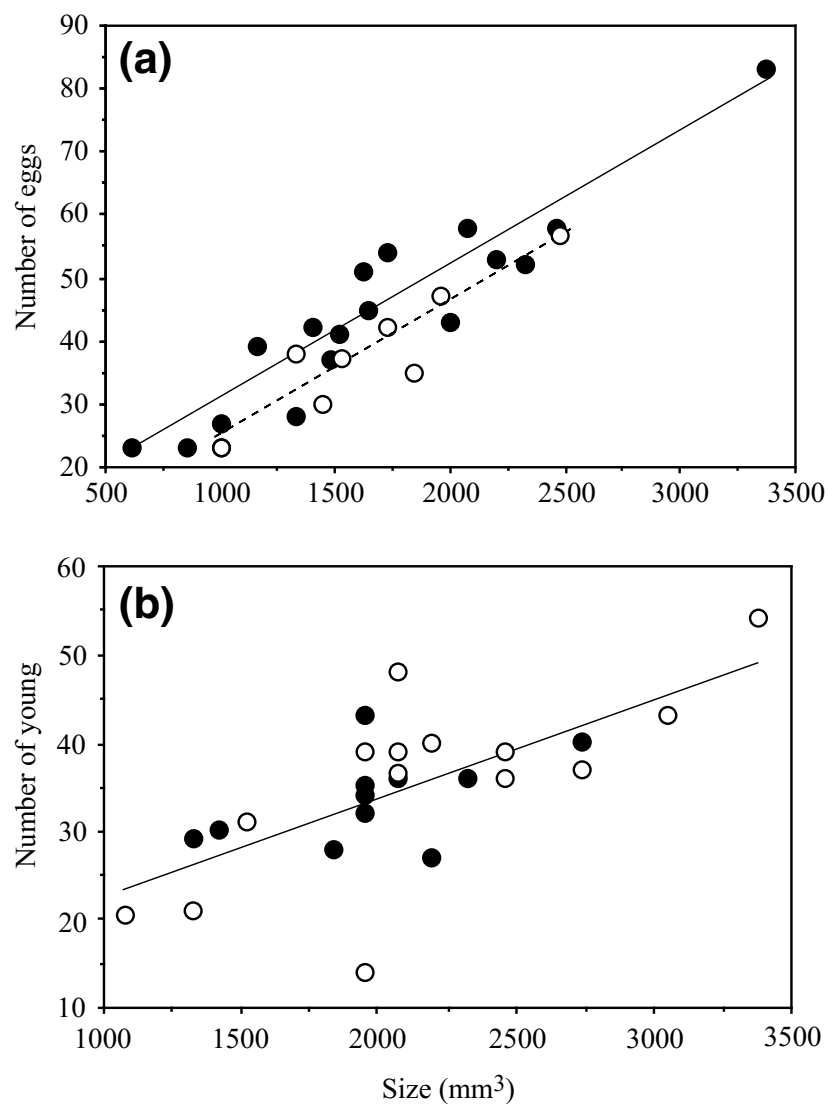

Fig. 1 Fecundity and fertility of Oniscus asellus females according to their size and their Wolbachia infection status. (a) Fecundity. Black circles and solid line: uninfected females $\left(y=0.021 x+8.49 ; r^{2}=0.877\right)$; open circles and dashed line: infected females $\left(y=0.021 x+3.147 ; r^{2}=0.833\right)$. (b) Fertility. Black circles: uninfected females; open circles: infected females. The relationship between size and fertility was $y=0.011 x+11.25 ; r^{2}=0.479$.

Table 1 Sex ratio and number of young in the broods of Oniscus asellus females captured gravid in the wild, according to their Wolbachia infection status

\begin{tabular}{lccccc}
\hline & \multicolumn{2}{c}{1995 sample } & & \multicolumn{2}{c}{1998 sample } \\
\cline { 2 - 3 } & Wo + & Wo- & & Wo + & Wo- \\
\hline Number of females producing offspring & 7 & 7 & & 14 & 11 \\
Total offspring & 326 & 661 & & 499 & 370 \\
Male offspring & 121 & 335 & & 80 & 187 \\
Number of brood per female (mean) & 2.6 & 3.7 & & 1 & 1 \\
\% males in the broods (mean) & 37.1 & 50.7 & & 16.0 & 50.5 \\
(SE) & $(5.2)$ & $(2.7)$ & & $(3.9)$ & $(2.3)$ \\
Number of young/brood (mean) & 16.5 & 25.9 & & 35.6 & 33.6 \\
(SE) & $(3.0)$ & $(1.9)$ & & $(2.9)$ & 1.5 \\
\hline
\end{tabular}

(C) The Genetical Society of Great Britain, Heredity, 83, 469-475. 
Table 2 The effect of Wolbachia injection on the sex ratio and the number of young per brood in an uninfected strain of Oniscus asellus

\begin{tabular}{lccccc}
\hline & \multicolumn{5}{c}{ Cross type (male $\times$ female) } \\
\cline { 2 - 4 } & $\mathrm{I} \times \mathrm{I}$ & $\mathrm{U} \times \mathrm{I}$ & $\mathrm{I} \times \mathrm{U}$ & $\mathrm{U} \times \mathrm{U}$ & ANOvA \\
\hline Number of crosses & 12 & 11 & 12 & 10 & \\
Total offspring & 754 & 728 & 576 & 448 & \\
Male offspring & 167 & 176 & 267 & 230 & \\
Brood per female (mean) & 2.6 & 2.3 & 2.0 & 1.9 & $F_{3,41}=1.99 ; P=0.13$ \\
(SE) & $(0.2)$ & $(0.3)$ & $(0.2)$ & $(0.2)$ & \\
\% males in the broods (mean) & $22.1^{\mathrm{a}}$ & $24.2^{\mathrm{a}}$ & $46.3^{\mathrm{b}}$ & $51.3^{\mathrm{b}}$ & $F_{3,41}=15.46 ; P<0.001 \dagger$ \\
(SE) & $(4.9)$ & $(3.7)$ & $(1.8)$ & $(2.9)$ & \\
Young per brood (mean) & 23.1 & 26.3 & 18.1 & 22.7 & $F_{3,41}=1.36 ; P=0.270$ \\
(SE) & $(3.2)$ & $(3.4)$ & $(1.9)$ & $(3.3)$ & \\
\hline
\end{tabular}

I: animals injected with Wolbachia; U: control uninfected animals.

$\dagger$ Test performed after arcsine transformation of the data.

${ }^{\mathrm{a}, \mathrm{b}}$ Values followed by the same letter were not significantly different after PLSD posthoc test.

An ANOVA revealed that the proportion of males significantly increased in the generations following injection in the I strains $\left(F_{2,86}=6.85 ; \quad P<0.002\right)$ (Fig. 2). A Fisher PLSD test showed that the proportions of males in generations 2 and 3 did not significantly differ $(P=0.67)$, whereas the proportion of males was significantly lower in the first generation than in the second $(P=0.002)$ or in the third $(P=0.002)$. The increase in the male proportion in the second and third generations was mainly caused by the appearance of females producing male-biased broods and all-male broods (Fig. 2), a phenomenon not found in the first generation. The proportion of balanced sex ratio broods was also high in the third generation. There was no correlation between the sex ratios in G2 and G3 (Fig. 2): females issued from female-biased broods were able to produce female-biased progenies, as well as male-biased progenies, whereas some females from male-biased broods produced female-biased progenies.

\section{Wolbachia transmission rates after transinfection}

The infection rate in female offspring was high $(91.1 \%$ of females tested harboured Wolbachia) and homogeneous between broods whatever their sex ratio $\left(\chi_{10}^{2}=15.46 ; P>0.05\right)$ (Table 3$)$. In male-biased progenies, the rare females all harboured Wolbachia. Such a complete infection in females was also found in half of the remaining progenies. Numerous males were infected, but the infection rate differed among broods $\left(\chi_{12}^{2}=55.68 ; P<0.01\right)$ : the lower the Wolbachia transmission rate in males, the lower the proportion of males in the broods $\left(y=-0.88 x+100.7 ; r^{2}=0.74 ; F_{1,12}=\right.$ 31.68; $P<0.001)$. Moreover, we found no infection in males from the all-male progenies (Table 4). In the progenies without male-biased sex ratios, the Wolbachia transmission rates were similar between male and female offspring $\left(\chi_{1}^{2}=0.84 ; P>0.05\right)$. Here, $87.7 \%$ offspring inherited Wolbachia.

Before the PCR test, the females were implanted with an androgenic gland. One or two moults after the implantation, all these females developed male secondary sexual characters (male differentiation of the second pleopod pair, bristles on pereiopods, etc.), regardless of their infection status. This masculinization indicated that Wolbachia were therefore unable to overcome the androgenic hormone in $O$. asellus, unlike the situation observed in A. vulgare.

\section{Discussion}

Results reported in this paper show that Wolbachia endosymbionts induce feminization, but not CI, in Oniscus asellus. A sex ratio distortion was found associated with the Wolbachia infection in the wild, and symbiont injection in uninfected strains induced female-biased sex ratios. The sex ratio varied strongly in the generations following the experimental transfer, and became less female-biased. This was caused by both imperfect feminization and loss of transmission. Paradoxically, this incomplete feminization gives the best argument for the occurrence of feminization. It has previously been showed that $O$. asellus is a species with female heterogamety (Juchault \& Rigaud, 1995). The females producing only sons are therefore genetic males (i.e. ZZ) feminized by Wolbachia, that failed to transmit symbionts to the following generation. In the absence of the feminizing activity of the cytoplasmic element, the offspring develop a phenotype consistent with their male (ZZ) genotype. Therefore, the increase of male proportion 


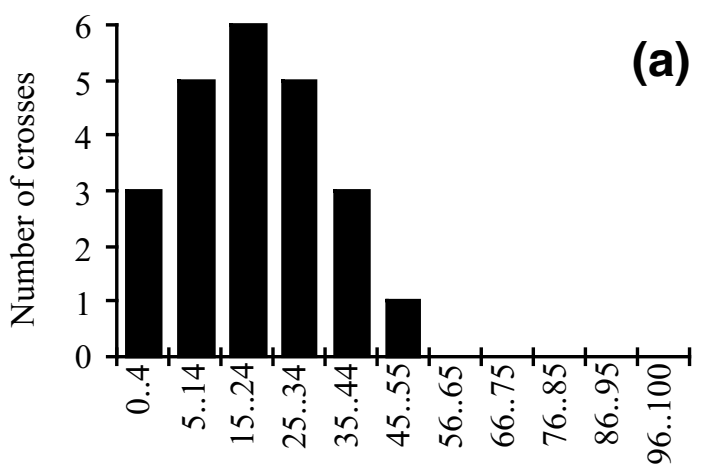

Proportion of males (\%)
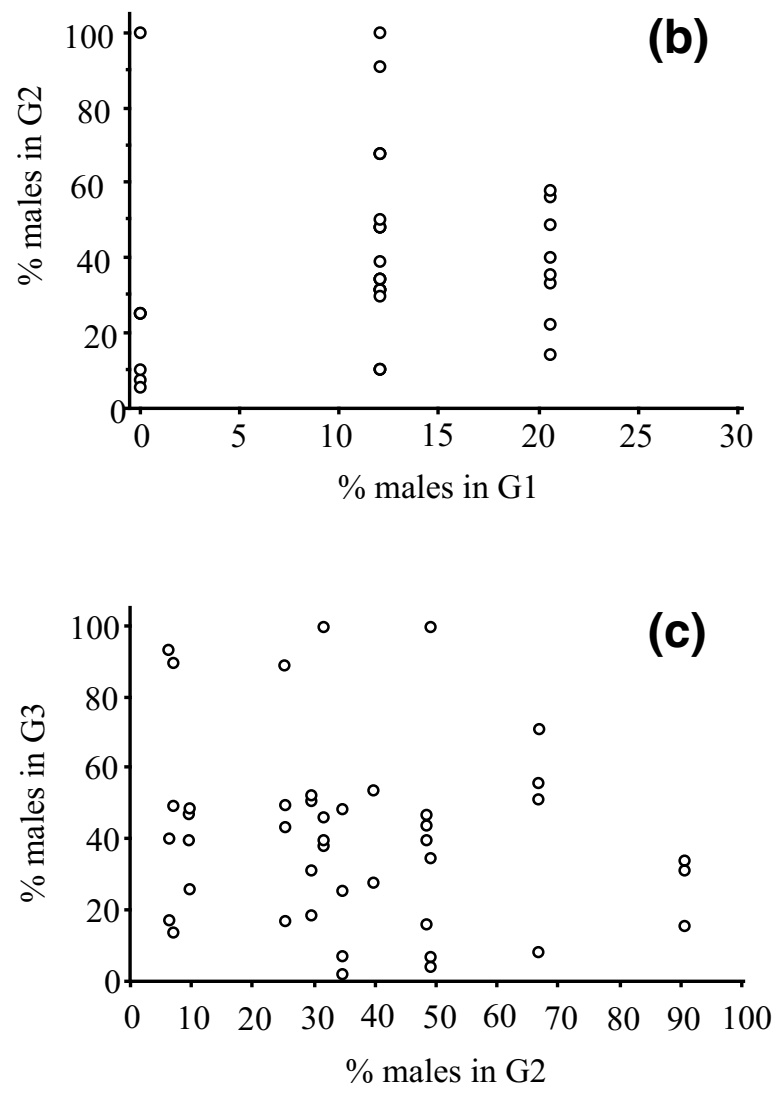

Fig. 2 Proportion of males in broods of Oniscus asellus uninfected females injected with Wolbachia, in the three generations following injection. (a) First generation (G1) after injection. Mean proportion of males $\pm \mathrm{SE}=23.1 \% \pm 3.0$. (b) Proportion of males in G2 plotted against proportion of males in G1. Several sisters of three G1 broods were crossed to obtain G2. Mean proportion of males $\pm \mathrm{SE}=44.0 \% \pm 5.3$ in G2. (c) Proportion of males in G3 plotted against proportion of males in G2. From two to four sisters from several G2 broods were crossed to obtain G3. $r^{2}=0.03 ; y=-0.17 x+$ $47.52\left(F_{1,41}=1.10 ; P=0.30\right)$. Mean proportion of males \pm $\mathrm{SE}=42.5 \% \pm 3.8$ in $\mathrm{G} 3$.
Table 3 Transmission rate of Wolbachia in 16 broods of Oniscus asellus after experimental transfer in uninfected lines, and comparison with the total sex ratio

\begin{tabular}{|c|c|c|c|c|c|}
\hline \multirow[b]{2}{*}{$\begin{array}{l}\text { Brood } \\
\text { no. }\end{array}$} & \multicolumn{2}{|c|}{ Males tested } & \multicolumn{2}{|c|}{ Females tested } & \multirow[b]{2}{*}{$\begin{array}{l}\text { Total offspring } \\
\text { (males; females) }\end{array}$} \\
\hline & Wo- & $\mathrm{Wo}+$ & Wo- & $\mathrm{Wo}+$ & \\
\hline 1 & - & - & 3 & 6 & $2 ; 28$ \\
\hline 2 & 1 & 2 & 3 & 12 & $4 ; 50$ \\
\hline 3 & 2 & 7 & 3 & 19 & $12 ; 105$ \\
\hline 4 & - & - & 0 & 8 & $4 ; 29$ \\
\hline 5 & 0 & 2 & 0 & 11 & $4 ; 14$ \\
\hline 6 & 1 & 11 & 0 & 20 & $15 ; 45$ \\
\hline 7 & 2 & 6 & 0 & 9 & $18 ; 19$ \\
\hline 8 & - & - & 2 & 8 & $54 ; 56$ \\
\hline 9 & 6 & 4 & 0 & 3 & $32 ; 4$ \\
\hline 10 & 4 & 6 & - & - & $25 ; 3$ \\
\hline 11 & 5 & 0 & 0 & 4 & $79 ; 7$ \\
\hline 12 & 7 & 3 & 0 & 3 & $38 ; 3$ \\
\hline 13 & 5 & 0 & - & - & $10 ; 0$ \\
\hline 14 & 10 & 0 & - & - & $88 ; 0$ \\
\hline 15 & 10 & 0 & - & - & $59 ; 0$ \\
\hline 16 & 10 & 0 & - & - & $36 ; 0$ \\
\hline
\end{tabular}

-, test not done; Wo-, individual uninfected by Wolbachia (negative PCR test); $\mathrm{Wo}_{+}+$, individual infected by Wolbachia (positive PCR test).

observed in generations following the transfer is not caused by the decrease in bacterial feminizing activity. The occurrence of $\mathrm{ZZ}$ females coupled with a constant incomplete feminization could be responsible for this. In other words, when feminization is incomplete in the broods of a $\mathrm{ZZ}$ neo-female, the entire brood can be male, whereas this is impossible in the first generation after inoculation, because recipient females are all WZ and can produce only a maximum of $50 \%$ males. No male-biased broods were observed in the wild. Our study was unable to discriminate between whether females naturally infected by Wolbachia are WZ infected with weak feminizers, or ZZ with strong feminizers. So we can not estimate if the $\mathrm{Z}$ chromosome reached fixation in lineages infected by Wolbachia, as is the case in A. vulgare (Rigaud et al., 1991). The inefficiency of feminization is probably not caused by symbiont strains differing in their feminizing ability, because there was no correlation in the male proportions between two generations after transinfection. Genetic control by the host cannot be dismissed, but, again, the lack of a correlation in sex ratios between these two generations indicates that there is no simple genetic mechanism involved. Furthermore, the recipient strains came from an uninfected population, where genes resisting feminization should not be selected. 
The type of feminization is different from that found in Armadillidium vulgare. The main difference is that males can be infected in $O$. asellus. There was therefore no direct relationship between the Wolbachia transmission rate and the sex ratio, and the feminizing capacity of the symbiont and its transmission rate probably evolved separately (Hatcher \& Dunn, 1995). Such a situation has already been found in the amphipod Gammarus duebeni infected with a microsporidian feminizing parasite: not all embryos inheriting the parasite were feminized (Terry et al., 1998). The cause of this inefficiency is unknown. In insects, variation in Wolbachia dosage induces variation in cytoplasmic incompatibility expression: the more numerous are Wolbachia in their male hosts, the more intense is the incompatibility in crosses (e.g. Breeuwer \& Werren, 1993; Bressac \& Rousset, 1993). Differences in Wolbachia-induced feminization may simply result from differences in bacterial dosage, the embryos harbouring a low dose of symbionts developing a phenotype consistent with their nuclear genotype, and those harbouring a high dose developing a female phenotype. However, staining methods generally used to detect Wolbachia (DAPI, Lacmoid) are inadequate in isopods (T. Rigaud, unpubl. obs.), and a reliable quantification method to test this hypothesis is still lacking. In addition, another phenomenon might explain the differences in feminization. This study showed that $O$. asellus females were sensitive to the masculinizing effect of the androgenic hormone, even when they possessed Wolbachia. The Wolbachia have therefore no effect on the hormone once the hormone is produced. The situation is different in $A$. vulgare where Wolbachia override the effect of the hormone. This effect can be seen as a backup system for the symbiont: if Wolbachia do not completely suppress differentiation of the androgenic gland, this second effect suppresses the effect of the hormone, and a male phenotype cannot appear. In $O$. asellus, there is no such 'second effect': once the gland develops, the development of a male phenotype is irreversible. We suggest that Wolbachia in A. vulgare evolved this 'second effect' to increase its feminizing power, an evolutionary state not reached in $O$. asellus.

Differences in host-symbiont relationships are probably responsible for the differences in feminization type between $A$. vulgare and $O$. asellus. Because both Wolbachia and hosts are genetically different in the two systems (Bouchon et al., 1998), it is hard to distinguish which genome (host or symbiont) of the association has the main role in controlling these effects. However, nuclear resistance alleles are known in $A$. vulgare. These alleles either overcome the symbiotic suppression of the androgenic gland differentiation (but in turn the Wolbachia is able to surpass this effect by suppressing the effect of the hormone; see Rigaud \& Juchault, 1993), or restrain the transmission of Wolbachia (Rigaud \& Juchault, 1992). So, perhaps the Wolbachia of $O$. asellus did not evolve a total efficiency of action/transmission because of the lack of host resistance. The coevolutionary scenario would therefore be of a 'Red Queen' type, the efficiency of feminization increasing only after the resistance of the host. Such a hypothetical scenario must be confirmed. Trans-specific infections could help to test this hypothesis, by following the progress of the infection after inoculation of different Wolbachia types in different female hosts.

Finally, our results suggest that Wolbachia induces a slight negative effect on host fecundity in $O$. asellus, an effect already found in Drosophila simulans (Hoffmann et al., 1990). But a negative effect on host fitness is not a general effect of Wolbachia, because positive effects on fecundity have also been reported (Stolk \& Stouthamer, 1995; Poinsot \& Merçot, 1997; Vavre et al., 1999). Furthermore, this negative effect was not found when the adult offspring of infected vs. uninfected $O$. asellus females were compared. This could suggest that a better survival of infected offspring could counterbalance the negative effect of the bacteria on fecundity. However, the difference in fecundity found in this study was weak, and we may conclude that Wolbachia has no obvious effect on the host other than sex ratio distortion.

\section{References}

BOUCHON, D., RIGAUd, T. AND JUCHAULT, P. 1998. Evidence for widespread Wolbachia infection in isopod crustaceans: molecular identification and host feminization. Proc. $R$. Soc. B, 265, 1081-1090.

Breeuwer, J. A. AND Werren, J. H. 1993. Cytoplasmic incompatibility and bacterial density in Nasonia vitripennis. Genetics, 135, 565-574.

BRESSAC, C. AND ROUSSET, F. 1993. The reproductive incompatibility system in Drosophila simulans, DAPI-staining analysis of the Wolbachia symbionts in sperm cysts. J. Invert. Pathol., 61, 226-230.

COSMIDES, L. AND TOOBY, J. 1981. Cytoplasmic inheritance and intragenomic conflict. J. Theor. Biol., 89, 83-129.

HATCHER, M. J. AND DUNN, A. M. 1995. Evolutionary consequences of cytoplasmic inherited feminizing factors. Phil. Trans. R. Soc. B, 348, 445-456.

HOFFMANN, A. A., TURELLI, M. AND HARSHMAN, L. G. 1990. Factors affecting the distribution of cytoplasmic incompatibility in Drosophila simulans. Genetics, 126, 933-948.

HURST, L. D. 1993. The incidences, mechanisms and evolution of cytoplasmic sex ratio distorters in animals. Biol. Rev., 68 , 121-193.

JUChault, P. AND Legrand, J. J. 1985. Contribution à l'étude du mécanisme de l'état réfractaire à l'hormone androgène chez les Armadillidium vulgare Latr. (Crustacé, Isopode, 
Oniscoide) hébergeant une bactérie féminisante. Gen. Comp. Endocrinol., 60, 463-467.

JUCHAUlT, P. AND RIGAUD, T. 1995. Evidence for female heterogamety in two terrestrial crustaceans and the problem of sex chromosome evolution in isopods. Heredity, 75, 466-471.

JUCHAUlT, P., FRELON, M., BOUCHON, D. AND RIGAUd, T. 1994. New evidence for feminizing bacteria in terrestrial isopods: evolutionary implications. C. R. Acad. Sci. Paris, Ser. III, 317, 225-230.

KAGEYAMA, D., HOSHIZAKI, S. AND ISHIKAWA, Y. 1998. Femalebiased sex ratio in the Asian corn borer, Ostrinia furnacalis: evidence for the occurrence of feminizing bacteria in an insect. Heredity, 81, 311-316.

LEGRAND, J. J. 1958. Mise en évidence histologique et expérimentale d'un tissu androgène chez les Oniscoïdes. C. $R$. Acad. Sci. Paris Série D, 247, 1238-1241.

MARTin, G., JUChAUlt, R. AND Legrand, J. J. 1973. Mise en évidence d'un micro-organisme intracytoplasmique symbiote de l'Oniscoïde Armadillidium vulgare L., dont la présence accompagne l'intersexualité ou la féminisation totale des mâles génétiques de la lignée thélygène. $C$. $R$. Acad. Sci. Paris, Sér. D, 276, 2313-2316.

POINSOT, D. AND MERÇOT, H. 1997. Wolbachia infection in Drosophila simulans: does the female host bear a physiological cost? Evolution, 51, 180-186.

RIGAUD, T. 1997. Inherited microorganisms and sex determination of arthropod hosts. In: O'Neill, S. L. Hoffmann, A. A. and Werren, J. H. (eds) Influential Passengers, Inherited Microorganisms and Arthropod Reproduction, pp. 81-101. Oxford University Press, Oxford.

RIGAUD, T. AND JUCHAUlt, P. 1992. Genetic control of the vertical transmission of a cytoplasmic sex factor in Armadillidium vulgare Latr. (Crustacea, Oniscidea). Heredity, 68, 47-52.
RIGAUd, T. AND JUCHAUlt, P. 1993. Conflict between feminizing sex ratio distorters and an autosomal masculinizing gene in the terrestrial isopod Armadillidium vulgare Latr. Genetics, 133, 247-252.

Rigaud, T., JUChault, P., AND MOcQuARD, J. P. 1991. Experimental study of temperature effects on the sex ratio of broods in terrestrial Crustacea Armadillidium vulgare Latr. Possible implication in natural populations. J. Evol. Biol., 4, 603-617.

Rousset, F., BOUChON, D., PINTUREAU, B., JUChAUlt, P. AND SOLIGNAC, M. 1992. Wolbachia endosymbionts responsible for various alterations of sexuality in arthropods. Proc. $R$. Soc. B, 250, 91-98.

STOLK, C. AND STOUTHAMER, R. 1995. Influence of a cytoplasmic incompatibility-inducing Wolbachia on the fitness of the parasitoid wasp Nasonnia vitripennis. Proc. Exp. Appl. Ent., 7, 33-37.

SUTtON, S. L., HASSAL, M., WILlOWS, R., DAVID, R. C., GRUND, A. AND SUNDERLAND, K. D. 1984. Life histories of terrestrial isopods: a study of intra- and interspecific variation. Symp. Zool. Soc. Lond., 53, 269-294.

TERRY, R. S., SMITH, J. E. AND DUNN, A. M. 1998. Impact of a novel, feminizing microsporidium on its crustacean host. J. Eukaryot. Microbiol., 45, 497-501.

VAVRe, F., GIRIN, C. AND Boulétreau, M. 1999. Phylogenetic status of a fecundity-enhancing Wolbachia that does not induce thelytoky in Trichogramma. Insect Mol. Biol., 8, 67-72.

WERREN, J. H. AND O'NEILL, S. L. 1997. The evolution of heritable symbionts. In: O’Neill, S. L., Hoffmann, A. A. and Werren, J. H. (eds) Influential Passengers, Inherited Microorganisms and Arthropod Reproduction, pp. 1-41. Oxford University Press, Oxford. 